07

\title{
Модуль Юнга и коэффициент Пуассона двумерно протяженного колонного графена
}

\author{
(C) А.С. Колесникова, М.М. Мазепа
}

Саратовский национальный исследовательский государственный университет им. Н.Г. Чернышевского, Саратов, Россия

E-mail: Kolesnikova.88@mail.ru

(Поступила в Редакцию 21 февраля 2018 г.)

Проведено теоретическое исследование модуля Юнга и коэффициента Пуассона двумерно протяженного колонного графена при одноосном растяжении. Рассмотрено влияния длин и диаметров нанотрубок, входящих в состав композита. Численные эксперименты осуществлялись с использованием минимального структурного звена и периодических граничных условий методом функционала плотности. Выявлены численные значения модулей Юнга композита при его растяжении вдоль нормали к графеновому полотну, с увеличением длин углеродных нанотрубок (УНТ) в композите, а также численные значения модулей Юнга композита при его растяжении по направлениям графенового полотна, с увеличением длин углеродных нанотрубок композита. Установлено, что величина коэффициента Пуассона для такого типа композитов составляет 0.025 .

Работа выполнена при финансовой поддержке Президентской стипендии 2016-2018 гг. (проект No СП-2502.2016.1).

DOI: 10.21883/FTT.2018.09.46397.041

\section{1. Введение}

Актуальной задачей в области усовершенствования работы современных наноустройств является создание композитного материала с уникальными свойствами, который будет использоваться в качестве элементной базы этих наноустройств. Новый виток в области развития таких материалов связан с синтезом и исследованием свойств композитных углеродных наноструктур на основе углеродных нанотрубок (УНТ) и графена. УНТ и графен часто служат составными частями композитных материалов для достижения высоких механических характеристик $[1,2]$. Это связано тем, что углеродные нанотрубки и графен обладают уникальными свойствами: механическая прочность [3-5], высокая теплопроводность [6], анизотропия электронных свойств $[7,8]$ и т.д.

В настоящее время синтезируемые и моделируемые композитные материалы, состоящие из УНТ и графена, отличаются конфигурацией структурных элементов и способом их соединения [9-14]. Одним из таких композитных материалов является композит - колонный графен, структурное звено которого образуется графеновым листом с вертикально ориентированными углеродными нанотрубками, присоединенными к графеновому листу химическими связями. При образовании композита края УНТ остаются открытыми, а в графеновом листе образуются отверстия размером равным диаметру УНТ. Данные структуры активно синтезируются [9,15-19], а уникальность их электронных [20,21], механических [22-26] и теплопроводящих [26,27] свойств делает возможным их применение в наноэлектронике [20,28-35], энергохранилище [28-33] и теплообменном оборудовании [27].
Для усовершенствования работы устройств наноэлектроники одним из важнейших свойств, которым должен обладать материал, являются прочностные свойства. В связи с этом необходимо наиболее детально изучать механические свойства колонного графена, несмотря на активное исследование механических свойств данного материала [22-26].

В настоящее время не найдено работ по исследованию механических свойств двумерно протяженного колонного графена при одноосном растяжении. Целью данной работы является теоретическое исследование модуля Юнга и коэффициента Пуассона двумерно протяженного колонного графена при одноосном растяжении. Проводилась оценка влияния длин и диаметров нанотрубок, входящих в состав композита. Исследование механических свойств нанокомпозитов осуществлялось на основе минимального структурного звена (элементарной ячейки) с использованием периодических граничных условий методом функционала плотности.

\section{2. Объект и метод исследования}

Объектом исследования является структура колонного графена, образованная графеновым листом, к которому перпендикулярно графеновой плоскости располагается углеродная нанотрубка armchair. В графеновом полотне в местах присоединения УНТ образованы отверстия, по форме и размеру соответствующие сечению УНТ, края УНТ остаются открытыми. Нанотрубки в композите располагаются в шахматном порядке. Тип киральности нанотрубок armchair был выбран исходя из того, что, согласно экспериментальным данным [36], нанотрубки такой киральности обладают высокими прово- 


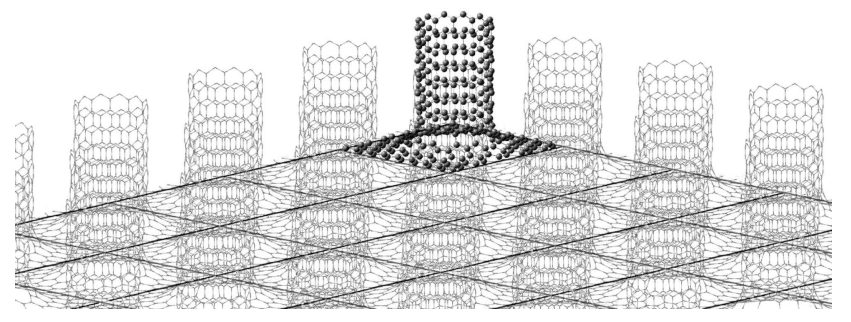

Рис. 1. Фрагмент двумерно протяженного атомарного композита - колонный графен. Жирным цветом выделена элементарная ячейка композита.

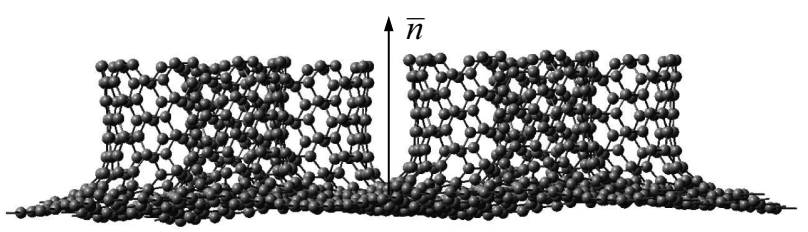

Рис. 2. Растяжение вдоль нормали (normal) к графеновому полотну. $n-$ нормаль к графеновому полотну.

дящими свойствами, а значит, построенный на их основе композит будет являться перспективным материалом для применения в наноэлектронике. Все УНТ в рамках одного композита обладают одинаковой геометрией: одинаковой длиной и диаметром (рис. 1).

Для исследования модуля Юнга и коэффициента Пуассона двумерно протяженного колонного графена проводилось одноосное растяжение композитов в каждом из трех ортонормированных направлениях: вдоль торца armchair графенового полотна, вдоль торца zigzag графенового полотна и вдоль нормали (normal) к графеновому полотну. Под растяжением вдоль нормали (normal) к графеновому полотну понимается растяжение вдоль оси УНТ (рис. 2). Алгоритм исследования модуля Юнга и коэффициента Пуассона представлен в работе [5]. Композит равномерно растягивался на $3 \%$ относительно первоначальной длины.

\section{3. Механические свойства двумерно протяженного колонного графена}

Исследования механических свойств двумерно протяженного колонного графена проводились на серии композитов. В серии изменялись длины и диаметры УНТ (таблица). В пределах одного композита длины и диаметры УНТ, а также расстояния между трубками оставались постоянными. Расстояния между стенками трубок во всех исследуемых композитах не изменялись и составили $14 \AA$.

При использовании алгоритма, представленного в работе [5], получены результаты исследования модуля
Геометрические размеры исследуемых моделей колонного графена

\begin{tabular}{r|c|c|c|c}
\hline Диаметр & $\begin{array}{c}\text { Интервал длин нанотрубок } \\
\text { для серии композитов } \\
\text { с одинаковым диаметром } \\
\text { нанотрубок, }\end{array}$ & $\begin{array}{c}\text { Размер элементарной } \\
\text { ячейки графенового } \\
\text { листа, } \AA\end{array}$ \\
\cline { 2 - 5 } & $\min$ & $\max$ & zigzag & armchair \\
\hline 5.47 & 4.10 & 16.70 & 15.99 & 16.32 \\
8.01 & 5.37 & 13.96 & 18.18 & 19.63 \\
12.12 & 3.95 & 10.10 & 20.13 & 21.20
\end{tabular}

Юнга для протяженного колонного графена (рис. 3-5). Результаты обобщены относительно направлений исследования модуля Юнга: вдоль торца armchair графенового полотна, вдоль торца zigzag графенового полотна и вдоль нормали (normal) к графеновому полотну (вдоль УНТ).

Из результатов видно, что модуль Юнга протяженных композитов увеличивается с увеличением длин УНТ в композите при исследовании вдоль нормали к

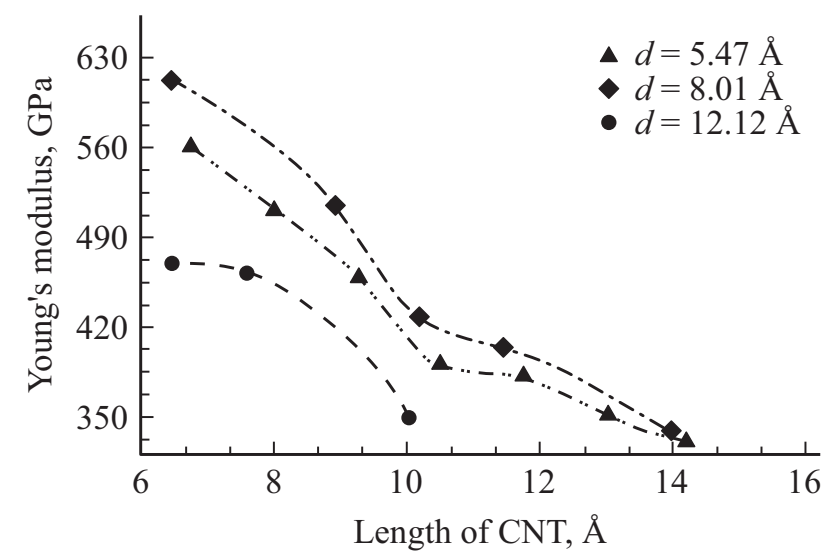

Рис. 3. Зависимость величины модуля Юнга, соответствующего направлению armchair, протяженного колонного графена.

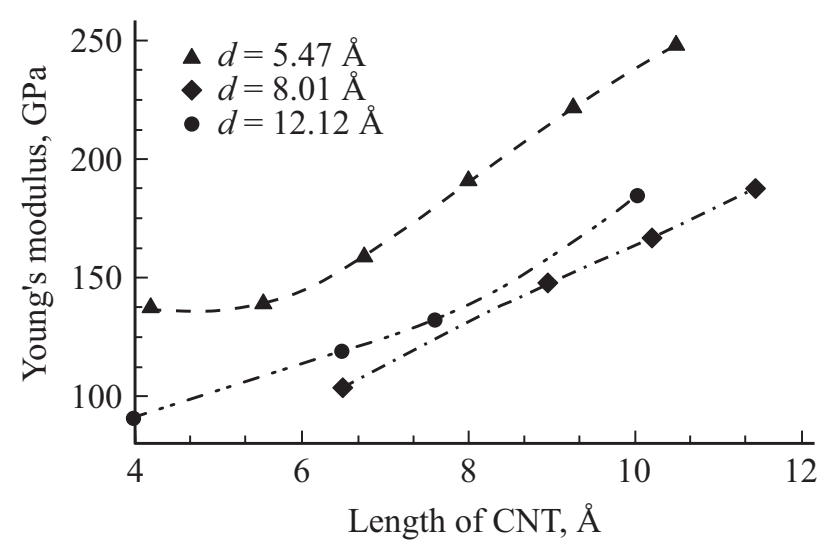

Рис. 4. Зависимость величины модуля Юнга, соответствующего направлению zigzag, протяженного колонного графена. 


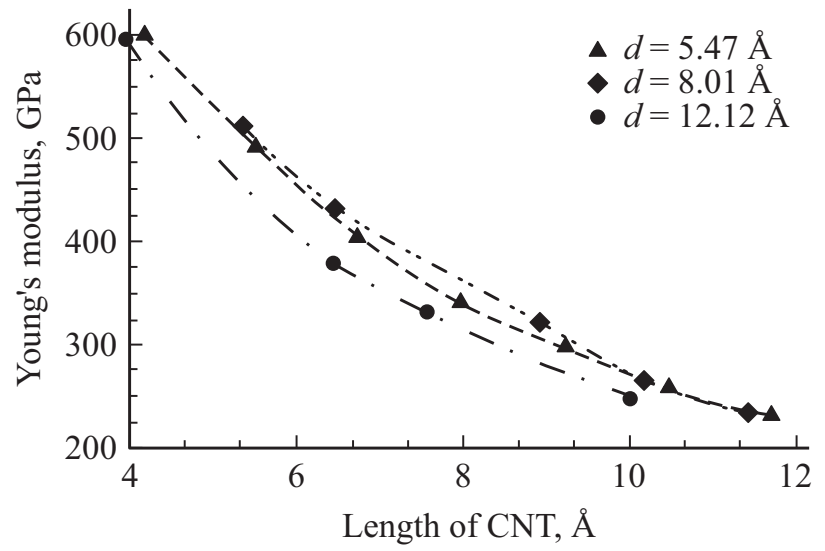

Рис. 5. Зависимость величины модуля Юнга, соответствующего направлению нормали к графеновому полотну, протяженного колонного графена.

поверхности графенового полотна и уменьшается при исследовании вдоль направлений графенового полотна. Из графиков видно, что прочность композита при растяжении вдоль направлений графенового полотна превосходит прочность при растяжении вдоль нормали к графеновому полотну.

Порядок значений модуля Юнга для каждого из трех одноосного растяжения согласуется с результатами для многослойных композитов (композитов, имеющих несколько графеновых слоев, между которыми располагаются углеродные нанотрубки) [22]. Однако на основе работы [22] судить о качественной картине изменения модуля Юнга не имеется возможным, так как в работе [22] имеется только по два численных значения модуля Юнга при изменении длины УНТ и расстояния между УНТ.

Проведено исследование зависимости коэффициента Пуассона от геометрических размеров УНТ композита. Установлено, что коэффициент Пуассона не зависит от размеров УНТ и направления исследования. Полученный коэффициент Пуассона составляет 0.025, что относит протяженный колонный графен к хрупким материалам, у которых модуль Юнга на сжатие превосходит модуль Юнга на растяжение. Данный результат согласуется с результатами работы [22].

\section{4. Заключение}

В работе представлены результаты теоретического исследования зависимости модуля Юнга и коэффициента Пуассона двумерно протяженного углеродного композита - колонного графена при одноосном растяжении на $3 \%$ от геометрических размеров УНТ - длин и диаметров.

Результаты численного эксперимента показали, что:

- модуль Юнга композита, при его растяжении вдоль нормали к графеновому полотну, увеличивается с увеличением длин УНТ в композите;
- модуль Юнга композита, при его растяжении по направлениям графенового полотна, уменьшается с увеличением длин УНТ композита.

Выявлено, что прочность на растяжение в направлениях графенового полотна превышает прочность на растяжение в направлении нормали к графеновому полотну.

Исследован коэффициент Пуассона протяженного колонного графена. Установлено, что величина коэффициента Пуассона не зависит от направления исследования, длин и диаметров УНТ и составляет 0.025 .

По результатам исследований наибольшей прочностью на растяжение в любом из трех направлений (вдоль торца armchair графенового полотна, вдоль торца zigzag графенового полотна и вдоль нормали (normal) к графеновому полотну (вдоль УНТ)) обладает протяженный композит, с диаметром трубок $5.47 \AA$ и с длиной трубок $4.18 \AA$.

Можно предположить, что полученные результаты получат широкое применение в развитии электроники, а исследованные композиты получат применение в автоэлектронной эмиссии.

\section{Список литературы}

[1] О.Е. Глухова, А.С. Колесникова, И.Н. Салий, М.М. Слепченков. Вестн. Самарского гос. ун-та 9, 102 (2013).

[2] S. Vadukumpully, J. Paul, N. Mahanta, S. Valiyaveettil. Carbon 49, 198 (2011).

[3] А.В. Елецкий. УФН 177, 233 (2007).

[4] Е.Д. Грайфер, В.Г. Макотченко, А.С. Назаров, С.Д. Ким, В.Е. Федоров. Успехи химии 80, 784 (2011).

[5] О.Е. Глухова, А.С. Колесникова, Г.В. Торгашов, З.И. Буянова. ФТТ 52, 1240 (2010).

[6] А.Г.Проневский, М.С. Тиванов. Вестн. БГУ. Сер. 1. Физика. Математика. Информатика 1, 48 (2015).

[7] М.В. Харламова. УФН 183, 1145 (2013).

[8] А.В. Елецкий. УФН 172, 401 (2002).

[9] Y. Zhu, L. Li, C. Zhang, G. Casillas, Z. Sun, Z. Yan, G. Ruan, Z. Peng, A.R.O. Raji, C. Kittrell, R.H. Hauge, J.M. Tour. Nature Commun. 3, 1 (2012).

[10] J.H. Deng, F.J. Wang, L. Cheng, B. Yu, G.-Z. Li, X.-G. Hou, D.-J. Li, G.-A. Cheng. Mater. Lett. 124, 15 (2014).

[11] V. Varshney, S.S. Patnaik, A.K. Roy, G. Froudakis, B.L. Farmer. ACS Nano 4, 1153 (2010).

[12] E. Pop, V. Varshney, A.K. Roy. MRS Bull. Mater. Res. Soc. 37, 1273 (2012).

[13] J. Gong, P. Yang. RSC Adv. 4, 19622 (2014).

[14] Y. Wu, T. Zhang, F. Zhang, Y. Wang, Y. Ma, Y. Huang, Y. Liu, Y. Chen. Nano Energy 1, 820 (2012).

[15] V.A. Labunov, B. G. Shulitski, A.L. Prudnikova, Y.P. Shaman, A.S. Basaev. Semicond. Phys. Quantum Electron. Optoelectron. 13, 137 (2010).

[16] F. Du, D. Yu, L. Dai, S. Ganguli, V. Varshney, A.K. Roy. Chem. Mater. 23, 4810 (2011).

[17] V. Jousseaume, J. Cuzzocrea, N. Bernier, V.T. Renard. Appl. Phys. Lett. 98, 123103 (2011)

[18] N.D. Kim, Y. Li, G. Wang, X. Fan, J. Jiang, L. Li, Y. Ji, G. Ruan, R.H. Hauge, J.M. Tour. Nanoletters 16, 1287 (2016).

[19] О.Е. Глухова, А.С. Колесникова, М.М. Слепченков, Д.С. Шмыгин. ФТТ 57, 994 (2015). 
[20] О.Е. Глухова, А.С. Колесникова, М.М. Слепченков, Г.В. Савостьянов, Д.С. Шмыгин. Радиотехника 7, 64 (2015).

[21] R. Shahsavari, N. Sakhavand. Carbon 95, 699 (2015).

[22] S. Sihn, V. Varshney, A.K. Roy, B.L. Farmer. Carbon 50, 603 (2012).

[23] C.H. Wang, T.H. Fang, W.L. Sun. J. Phys. D 47, 405 (2014).

[24] Y.C. Wang, Y.B. Zhu, F.C. Wang, X.Y. Liu, H.A. Wu. Carbon 118, 588 (2017).

[25] M. Moradi, J.A. Mohandesi. AIP Adv. 5, 117143 (2015).

[26] K. Xia, H. Zhan, Y. Wei, Y. Gu. Beilstein J. Nanotechnology 5, 329 (2014).

[27] T.-H. Fang, W.-J. Chang, Y.-C. Fan, W.-L. Sun. Jpn J. Appl. Phys. 55, 040301 (2016).

[28] P. Lv, X.-W. Tan, K.-H. Yu, R.-L. Zheng, J.-J. Zheng, W. Wei. Carbon 99, 222 (2016).

[29] X. Wang, G. Sun, P. Chen. Frontiers Energy Res. 2, 1 (2014).

[30] T. Mayalagan, X. Dong, P. Chen, X. Wang. J. Mater. Chem. 2, 5286 (2012).

[31] K.P. Prasad, Y. Chen, P. Chen. Appl. Mater. Interfaces 6, 3387 (2014).

[32] M.G. Hahm, A.L.M. Reddy, D.P. Cole, M. Rivera, J.A. Vento, J. Nam, H.Y. Jung, Y.L. Kim, N.T. Narayanan, D.P. Hashim, C. Galande, Y.J. Jung, M. Bundy, S. Karna, P.M. Ajayan, R. Vajtai. Nano Lett. 12, 566 (2012).

[33] H. Ji, L. Zhang, M.T. Pettes, H. Li, S. Chen, L. Shi, R. Piner, R.S. Ruoff. Nano Lett. 12, 2446 (2012).

[34] Y. Zhang, Z. Zhen, Z. Zhang, J. Lao, J. Wei, K. Wang, F. Kang, H. Zhu. Electrochem. Acta 157, 131 (2015).

[35] D.C. Higgins, M.A. Hoque, F. Hassan, J.-Y. Choi, B. Kim, Z. Chen. ACS Catal. 4, 2734 (2014).

[36] R. Saito, G. Dresselhaus, M.S. Dresselhaus. Physical Properties of Carbon Nanotubes. World Sci. Publ., London (1998). P. 259 .

Редактор Т.Н. Василевская 